\title{
Paradigm Shift in Teaching Communication Skills Course in a Tanzanian University: An Assessment and Lessons for Other Universities
}

\author{
Hashim Issa Mohammed \\ Department of Language Studies, Sokoine University of Agriculture, Morogoro, Tanzania
}

Email address:

mohhashim@gmail.com, mohhashim@sua.ac.tz

\section{To cite this article:}

Hashim Issa Mohammed. Paradigm Shift in Teaching Communication Skills Course in a Tanzanian University: An Assessment and Lessons for Other Universities. International Journal of Language and Linguistics. Vol. 6, No. 5, 2018, pp. 173-185. doi: 10.11648/j.ijl1.20180605.15

Received: August 17, 2018; Accepted: September 25, 2018; Published: October 25, 2018

\begin{abstract}
Communication Skills Courses (henceforth CSCs) are offered in many universities and other higher learning institutions in Tanzania. The CSCs were designed to enable students cope with their university studies. Besides CSCs, remedial English courses became an additional component because the language proficiency of undergraduate students was often found to be too low at the time of joining the university In the University under study, English remedial courses started to be offered in tandem with CSCs to all first year undergraduate students. However, over the years, since the introduction of the course, examiners have been concerned that the two tier CSCs arrangement has had little impact in improving English language proficiency and academic literacy among students. Accordingly, the Language Department at the University under reference took many measures redress the situation. These efforts amounted to a paradigm shift in the teaching of CSCs at the University. It is over two full academic years since the adoption of the new approach. The current study therefore aimed at assessing the implementation of the new approach. Specifically, the study wanted to find out how successfully the new approach has been in meeting the objectives of the changing trends in the teaching of English towards more communicative approaches in what is referred to here as paradigm shift. The data for this study were collected at one of the universities in Tanzania in the 2016/2017 academic year following a qualitative evaluation of the participants' perceptions, involvement, achievement, classroom observation, and documentary review. The study followed a communicative framework by Jacobs and Farrell, to assess the implementation of these elements in the new approach. The findings indicated few successes of the new approach especially in the area of curriculum integration where the concept of spiral and non-linear arrangement of topics proved effective in students learning. However, there were many challenges in the implementation of the new approach in the context of University under study and Tanzania generally, and revolved around large sizes, learner cantered, reading habits and critical thinking skills. The paper recommends that universities should invest in self-learning resource centres as additional avenues for learning outside classroom, encourage reading culture, and build capacity in handling large classes. Others include collaborating with preuniversity institutions especially secondary schools in working out common mechanism of addressing the problem through exchange of experience and best practices.
\end{abstract}

Keywords: Academic Communication, Remedial English, Study Skills, Communicative Framework, Higher Learning Institutions, University Studies

\section{Introduction and Problem Statement}

Communication Skills Courses (henceforth CSCs) have been offered in many universities and higher learning institutions in Tanzania. The offering of such academic communication courses is often placed in the mandate of Language Departments or Communication Skills Units. In the University under study, the CSCs are under the Department of Language Studies. In many universities in Tanzania, the introduction of $\mathrm{CSCs}$ is a historical phenomenon which is traceable back to the time these universities came into existence. For example, at the University under study, CSCs started during the University's establishment in the 1980s. The CSCs in all these universities 
were designed to help students through acculturation process of acquiring university culture of how to interpret and respond to questions, applying critical thinking skills, critical reading skills, critical writing skills, and argumentative skills which are essential in coping with their academic university studies. Thus, the course was mainly then construed as dealing with study skills. However, it became apparent that when students first join universities, their English language proficiency is too low for these students to benefit from academic communication and other University courses $[1,2]$ and thus fail to successfully undergo this acculturation process. This is despite the fact that English is the medium of instruction in secondary school and other pre university levels. In this respect, besides CSCs, remedial English courses became an additional component in the provision of CSCs courses to respond to both language and academic communicative needs of the newly enrolled undergraduate students.

In this regard, it became a policy matter to have both English remedial courses and CSCs introduced in all universities in Tanzania. The approach in which CSCs is offered varies across different universities, and so is the subject code. In many universities, the remedial English and study skills component are embedded as one Communication Skills course with a subject code beginning with LG, at the University of Dodoma, or CL at the University of Dar es Salaam. In the University under study, English remedial courses started to be offered in tandem with CSCs to all first year undergraduate students. Later during the years, the University started offering a two tier module of Communications Skills Courses, namely, Communication Skills I bearing the subject code SC 100 (henceforth CSCI) and Communication Skills II, bearing the subject code SC 101 (henceforth CSCII). Specifically, CSCI intended to address English and grammatical competence and started to be offered in Semester One of study. CSCS II, on the other hand, focused on study skills and academic communication problems which many students often encounter especially in the first year of their university studies [3]. The CSCs II has been offered in Semester Two of the First year of study. Over the years since the introduction of the course, examiners across the University had been concerned that the two tier CSCs arrangement has had little impact in improving English language proficiency and academic literacy among students (see [3, 4]). Based on these reasons, the Department of language studies decided to explore best practices in running the CSCs with a view of making these courses have the desired impact.

Accordingly, the Language Department in the University under reference embarked on several measures to address students' deficiencies in English and academic communication. Among them include a study visit to universities in West and South Africa to explore international best practices in the teaching of English. This measure was soon followed by a curriculum review of both CSCs, which were deemed to require major adjustments in the learning outcomes, course materials, and assessment procedures to have them aligned with communicative language teaching approaches. The Department also conducted training to its academic staff members, which was meant to reorient them to the changing perspectives of language teaching and learning. Among the areas covered for the training include, communicative language teaching approaches, studentcentred approaches, content based instruction, assessment practices, methodologies for handling large classrooms, and utilization of online resources. All of these were instrumental in the implementation of the revised curriculum.

In short, these efforts amounted to a paradigm shift in the teaching of Communication Skills Course at the University. The new curricular have been in place for four full academic years since its adoption. Over this period, members of staff in the Language Department are assumed to have gained significant experience and insights into the implementation of the new curriculum. The current study therefore, intends to assess the implementation of the revised curricular. Specifically, the study explores how successfully the revised curricular has been able to achieve the objectives of the changing trends in the teaching of English towards more communicative approaches in what is referred to here as paradigm shift. Secondly, the study sought to identify challenges which emerged during the implementation of the curricular and the associated approaches; and finally, to discuss implications of these findings for other universities including suggestions on the way forward.

In order to achieve these objectives, the researcher adopted a communicative framework by Jacobs and Farrell, [5], which draws much from the Communicative Language Teaching (CLT) Model, See [6]. The framework proposed is consistent with the changes which the Language Department put in place in addressing students' language and communication problems at the university under study. These changes were designed to suit current trends in the teaching of English, which consider English teaching and learning not as an end by itself, but as a means of negotiating meanings in various communicative interactions.

Jacobs and Farrell, [5] Communicative Framework is as shown in Figure 1. 


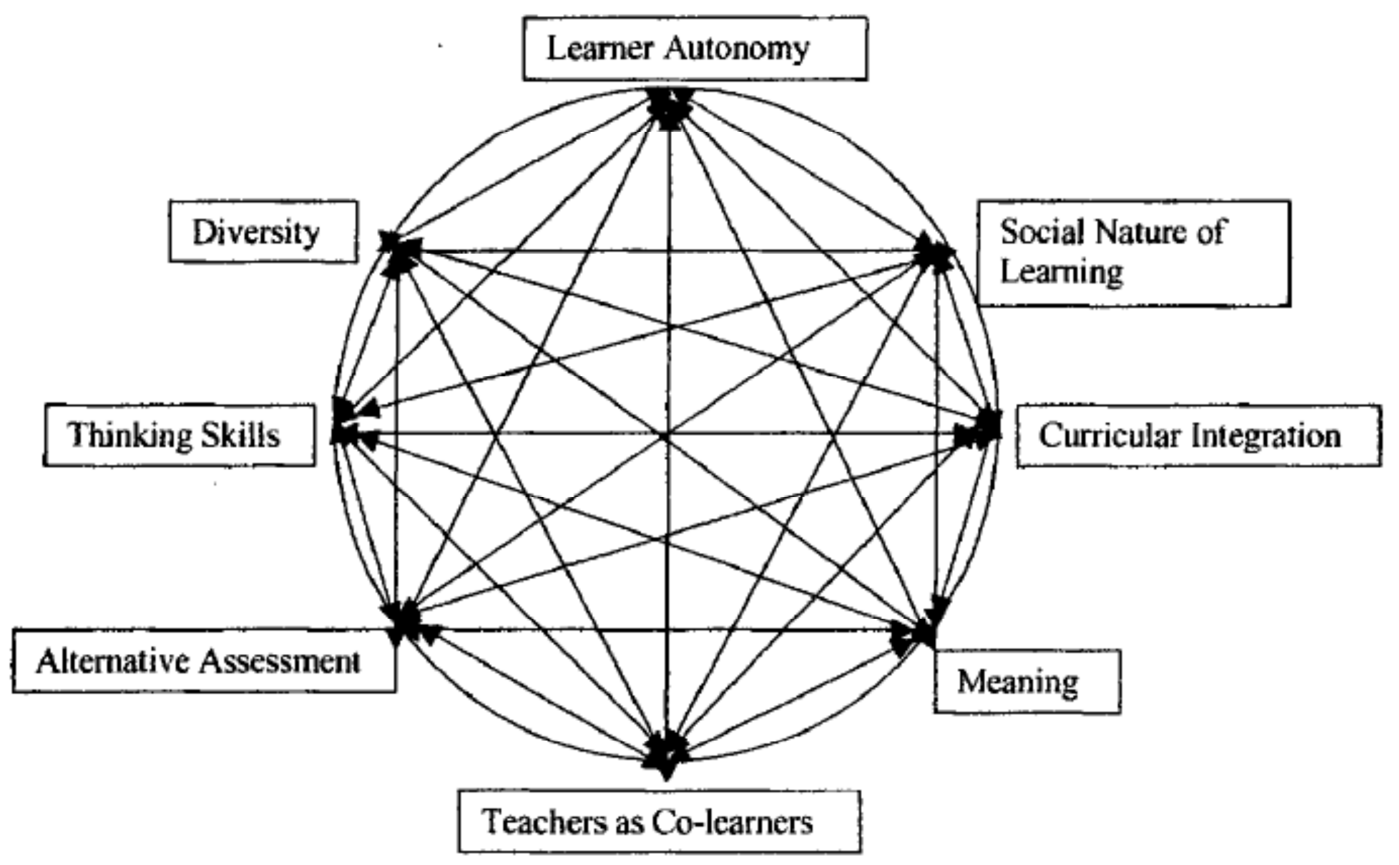

Source: Jacobs and Farrell [5], Communicative Framework,

Figure 1. Communicative Framework.

The underlying philosophy and practice of Communicative Framework [5] hinges on eight interdependent elements namely, (i) Learner autonomy; (ii); Social nature of learning; (iii) Curricular integration; (iv) Focus on meaning; (v) Diversity; (vi) Thinking skills; (vii) Alternative assessment; and (viii) Teachers as co-learners. These elements are shown in the circular Figure 1. The key assumption in this circular figure of the framework is that each of the components in the figure is interconnected with all the other components in the figure using back and forth pointing arrows. The implication of this illustration is that the success or failure of any one component in the model is inevitably linked to the success or failure of other components. The eight elements reflect a paradigm shift in second language education, and constitute the criteria in which communicative curricula can be evaluated. These elements are elaborated as follows.

\subsection{Learner Autonomy}

Learner autonomy is to do with learners taking responsibility of their own learning and be able, as Jacobs and Farrell [5] put it, 'to have some choices as to the what and how of the curriculum and, at the same time, they should feel responsible for their own learning and for the learning of those with whom they interact' [5.p 7]. This also goes in tandem with redefining the roles of teachers and learners to be consistent with what is espoused in the CLT model, whereby learners can now negotiate how their learning ought to be conducted; in other words, learners now have more rights to determine their learning processes where they are encouraged to develop their own leaning purposes [2, 5]).

\subsection{The Social Nature of Learning}

The social nature of learning looks at language learning as social practice, where the source of knowledge and ideas are not only teachers or individuals interacting with the learners but also there ought to be multiple sources of learning; and as Jacobs and Farrell [5.p 9] surmise, 'students learn via interacting with their environment, and the key features of that environment are the people with whom they come into contact' and these include not just language teachers, but also teachers of content subjects, peers and where appropriate mode speakers of the target language who are available in the community. This implies that classrooms are the micro environments where languages can be learned, but these micro environments should be supported by the macro environment, the society which classrooms painstakingly try to reflect. And it is in these macro environments where the learners would apply the knowledge and skills they have learned and acquired in the classroom for real communicative purposes. There are three issues alluded here, first the most effective learning can actually be done outside the classroom, where learners would practice language skills acquired in the classroom in real communicative situations. Furthermore, language learning, like learning any other skills (such as driving), is acquired through practice and not through learning about the language, which seems to inundate many language classroom practices. Second, drawing from Lynch, cited in [4] learning a language is like being involved in a sport where players have to work as a team. This augurs well with the social perspective of language learning practice, which highlights the importance of positive interdependence, '... the feeling among the members of a group that the group either sinks or swims together,' [5.p 9] and also that 'Positive interdependence helps students feel supported and belonging to the group and at the same time that they get motivated to try hard to assist the group in reaching its goals' [5] (italics 
added).

\subsection{Curricular Integration}

Curricular integration is construed as the teaching of various subject areas jointly with the aim of providing learners with the opportunity of seeing connection across these subject areas. Learners' appreciation of the links, according to Jacobs and Farrell [5. p 13] helps them to 'develop a stronger grasp of subject matter, a deeper purpose for learning and a greater ability to analyze situations in a holistic manner.'

There are two perspectives here; first is the perspective that language can be taught while teaching other subject contents. The perspective that students can learn language while learning their other subject contents has been widely acknowledged in the philosophy of content based instruction [4] and content based classroom [7]. In the context of the University under study, CSCs ought to be taught not as standalone courses but rather as a means of gaining access to the content in students' particular areas of specialisation. In other words, students ought to learn and be able to use English in order to complete academic tasks in their various courses of study (English for Academic Purposes). And secondly, as students learn their content subjects, they also immediately see the relevance of language in learning for example agricultural science, agricultural economics, statistics, and so on. In this respect, the involvement of instructors in other subject content areas in promoting the use of English among students in those disciplines is also critical since students are not only assisted to resolve their language problems but also they are provided with the opportunity of using language to negotiate meanings in other subjects. Elsewhere, this perspective has been successful through language instructors securing permission of using materials from instructors of other content areas to develop language courses. And according to Brinton and Jensen [8], 'By developing course materials from content courses on campus, language instructors can give students the skills necessary to be successful at their own college or university' (p. 134)

\subsection{Focus on Meaning}

'Research from cognitive psychology tells us that we learn best when we connect and store information in meaningful chunks' [5]. Similarly, literature [8, 9, 10] shows that language learning is most effective when is linked to meaningful usage. There are two perspectives in which the focus on meanings can entail; the first perspective is on learners' understanding of the language inputs which they (learners) are exposed to, and this can be in the level of words, phrases, or a whole chunk of a text. The second perspective relates to the meaning of particular topics, themes or sentences to the learners' life experiences; in other words, the manner in which the learners can relate these topics to their own life is critical in learning both the subject matter and the language item through which the subject content is expressed. This aspect discourages the teaching of language or grammatical tools which are removed from the students' life experiences, and which have heavy reliance on rote learning, including parrot copying of lesson notes and memorization. These parrot learning approaches, thought may have short term benefits, they may not be beneficial in enhancing learners' communicative competence which is espoused in the CLT.

\subsection{Teachers as Co-Learners}

The concept of teachers as co-learners in the Jacobs and Farrell, [5] communicative framework is an extension of the roles of teachers described in the Richards [6] CLT framework. While in the latter the role of a teacher is said to be that of a facilitator and a monitor in a cooperative approach to learning, in the former this role involves teachers' participation in the learning itself along with students and this may involve anything from asking questions and doing complex real-world tasks as part of lifelong learning. This role is emphasised especially because of the complexity and the constant changing nature of the world. According to Jacobs and Farrell [5. p 23] 'Teachers must take part in this never-ending quest and, indeed, model this process for their students. Teachers learn more about their subject areas as they teach. They also learn more about how to teach.' Apart from the concept of lifelong learning, which is emphasised in this element, there is the concept of considering learners as knowledge generators and where teaching and learning are seen 'as social processes where the students are active co-constructors of knowledge with their teachers' [5].

\subsection{Alternative Assessment}

Discussions on alternative assessment focus on the core of teaching and learning process itself. Any means of assessment that has been and continues to be proposed therefore has usually been influenced by what it means by student learning. In other words, just as the meaning of student learning was expanded from what students need to learn, to include students expectations of what they are able to do, so was the assessment instruments, to mirror, as the authors put it, 'more closely real-life conditions and involve thinking skills,' see [5]). This is what is described as standards and which, according to Jacobs and Farrell, encompasses two areas of learning: Content and performance standards. The former describe what students need to know and be able to do, while the latter describe how well students should be able to do something. 'The major shift inherent in the standards requires teachers to focus more on what students are learning than on what they are teaching-making output rather than input counts more' [5.p 20] (italics added). According to the authors, the new paradigm in the assessment informs a change in many ways including emphasis on meaning rather than form, the need for investigating the learning process, understanding of the social nature of learning (which necessitates the 'inclusion of peer assessment and the use of group tasks in assessment'), and 
'in keeping with notions of learner autonomy, students are more involved, understanding how they will be assessed and even participating in that assessment' [5].

\subsection{Thinking Skills}

There has been an increasing realisation that thinking skills are an important part of any education system, as information is readily available, but the problem is on how to put that information into better use. Accordingly, it is considered essential to enable learners acquire and use strategies that involve 'going beyond the information given and utilizing and building their higher-order thinking skills, also known as critical and creative thinking skills' [5]). Education psychologist Bloom (see [11]) has made a great contribution in this area on his Taxonomy of Cognitive Learning Domains, which describe intellectual behaviour or thinking skills which a learner needs to acquire at a university. This also includes as Bloom, cited in [5] puts it, 'applying information to other contexts, analyzing the features of a given phenomenon, synthesizing information to create something new and evaluating information and ideas'. The area of critical thinking has been linked to a major paradigm shift in CLT, first by the fact that thinking is a process, and as in any other process, the quality of the process rather than of the product is what is more emphasised; especially because as the saying goes, shoddy thinking is costly. Thinking skills is also said to promote other elements in the paradigm such as leaner autonomy where students are encouraged to 'connect the language learning they do in school with the world beyond' [5.p 18]. This connectivity also augurs well with social nature of learning where what is acquired in class can be related to real life situations outside classroom.

\subsection{Diversity}

The concept of diversity, which has been in common use, is the one involving mixing of students from different backgrounds in terms of education, language, social class, ethnicity, gender, geographical origin and the like in the same classroom. There has been an ongoing debate as to whether or not diversity has any educational benefits to the learner. On the one hand, the attempt of the old paradigm was 'to fit all students into a one-size-fits-all learning environment, with diversity viewed as an obstacle to be removed' [5.p 19] Earlier systems considered recognition of student differences as discriminatory, and led to the integrating even students with special needs to mainstream education systems. This ignored varying individual needs in coping with education demands in the mainstream education settings. In the new paradigm on the other hand, students are considered as individuals with diverse interests, identities and individualities which should be respected. In a language classroom, Teachers' role is to arbitrate this cultural and linguistic diversity as "classroom resource just as powerful as it is a social resource in the formation of new civic spaces and new notions of citizenship" [12].

These eight elements have been fundamental in the current study as criteria of assessing the teaching of Communication Skills Course within the paradigm shift framework of teaching language courses as communicative practice.

\section{Methodology}

\subsection{Participants}

The data for this study were collected from one of the universities in Tanzania as a case study in the 2016/2017 academic year. To assess the implementation of paradigm shift we used a number of strategies, but the main methodology was a qualitative evaluation of the participants' perceptions, involvement, and achievement. The qualitative evaluation also addresses classroom observation and documentary review.

\subsection{Sampling Procedure}

\subsubsection{Ethical Considerations}

This study followed standard procedures for social research, whereby permission was sought from the University and granted. All participants in the study willingly agreed to participate and confidentiality of the participants was strictly observed.

\subsubsection{Sampling Techniques}

The study followed purposive sampling, which involved the following respondents: four key informants; these were purposely selected on the basis of their position (they were all heading sections which were directly involved with the delivery of CSCs at the University under study). Eight course instructors for each CSCI and CSCII courses, and sixty (60) students from different degree programmes were involved. These degree programmes were categorized into ten (10) clusters depending on the nature and closeness of the disciplines. From each cluster six (6) participants were randomly selected to participate in the study.

\subsubsection{Instruments}

Several tools were used to collect data and these include key informant interviews, questionnaires, documentary analysis, and direct classroom observation. key informant interviews were mainly administered to the Dean of Faculty (now SMC College of Science Education), the Coordinator of the English Language Resource Centre, eight course instructors for each CSCI and CSCII courses, the Head of Department of Language Studies, one US ex-volunteer and technical expert and advisor. The interviews were aimed at determining the challenges in the design and implementation of the curricula around resources acquisition including textbooks, online materials, staff development program on Communicative Language Teaching, student centred approaches, assessment practices, and handling of large classes.

(i). Questionnaire, the study administered a Likert type questionnaire to a sample of eight (8) course instructors for each CSCI and CSCII courses and 60 students to determine their attitude towards the new 
programme and the change of language use behaviour.

(ii). Documentary analyses of current curricula for Communication Skills courses. This involved a review of two curricular documents and teaching and learning materials which were evaluated in the light of the evaluative framework as identified by Jacobs and Farrell [5]. It was envisioned that these materials would inform the study on eight features which a CLT curriculum and material should reflect.

(iii). Direct classroom Observation involved eight classes taught by different instructors. Each observation lasted for two hours. The observation aimed at analysing the learning environment, the role of the teacher as a co-learner, students' involvement/autonomy, teaching approaches, the use of teaching aids, and the use of English as a medium of instruction.

\subsection{Study Design and Data Analysis Method}

This study followed a case study research design where data were collected from a sample of respondents from a defined population as explained above. Data were analyzed using qualitative data analysis methods whereby thematic analysis approach was used. The thematic analysis in the current study involved the evaluation of the measures adopted by the Department in the University under study against the eight (8) elements as illustrated in the Jacobs and Farrell's Communicative model.

\section{Results}

As it was indicated in the background - the Department of Language Studies at the University under study made efforts which amounted to a paradigm shift in the teaching of Communication Skills Course. Since the implementation of this paradigm shift in the teaching of CSCs was assessed using Jacobs and Farrell [5] communicative framework, it is instructive to present the results in terms of the measures the Department adopted and the instructors teaching practice in line with this framework.

\subsection{Learner Autonomy}

In the University under study, the aspect of learner autonomy is reflected in the broader paradigm shift of teaching and learning approaches in the running of CSCs. In these approaches classroom interactions were expected to enable students participate in articulating their identities, that is, making sense of who they are, as learners and expressing their voices. According to Bamba (cited in [2]) 'Students have talents and therefore they need to be given opportunities to express them.' According to Bamba [2] 'small groups can help students to have another perspective of a given topic and build new understanding by confronting their ideas with those of other students'. The findings of the current study (classroom observation, students' questionnaires) indicate that instructors were encouraging students' participation through question and answer sessions, pair and share type of discussions, as well as some of the strategies that promote learner autonomy. Also the curricular was found to empower students to interact with the learning materials

For example in the student's activity book, Unit One has the following questions

Discuss these questions with other students. Be prepared to share your answers with the class.

1. Does this text generally tell the truth about men and women, in your opinion?

2. Are there any points that you do not agree with? Explain.

3. Is it right to make these points about men and women, or are these stereotypes?

Students' Activity Book Unit 1 [13].

In another place in the Students' activity Book Unit 1, (2014, p.10) there is an activity where students are required to look at the photo and respond to questions. After the response, students are supposed to do the following activity.

Activity:

Share what you wrote with a partner. Then, switch papers. Look at his/her answers. Underline the verbs in each sentence. Tell your instructor examples of verbs you underlined. In the last lesson we looked at how noun phrases can be subjects and objects. Now let's study verb phrases [13].

As we can see from this activity, the scoring of the students' responses was supposed to be done by students themselves. And since this was a warm-up activity, the topic of the lesson, which was verb phrases, was supposed to be explored by students themselves at the end of the activity.

These findings confirm that the teaching approaches were primarily in line with the paradigm shift proposed in the CLT model. As for the first hypothesis on student's empowerment, instructors were found to have done their best. However, there were still indications of the dominance of instructors' voice in the classroom interaction. In many classes observed most of the teaching involved lecture methods with students involvement only limited to responding to instructors' questions and carrying out activities as provided by the instructors as they deemed fit. As for the learning materials, which had plenty of students' activities, and which would have otherwise empowered students through pair and share, many of such activities were deliberately avoided. During interview sessions with instructors it was revealed that such activities were time consuming, and given the large class sizes if all activities were to be carried out by students then the coverage of the curricular and course material would have been compromised. For example one of the instructors had this to say,

Imagine, I have 300 students in my class, and if every students has to speak, then I would only be able to teach only a few topics in one unit ........ and ... there are three units for the entire course.

Therefore, in my case and ... I also think this is what others are also doing is that I skip all warm-ups activities' 
and many others then I involve pair work and or small group discussions (Staff interview, November 2017).

The foregoing presentation implies that the existing institutional framework is prohibitive against successful implementation of the model. It is impractical for instructors to follow all the course contents and provide all the students with the attention they deserve within the available limited time for the course and class sizes. In order for this component of the paradigm shift to succeed, there is need for deliberate efforts for institutions to review the teaching and learning systems so that students have enough time to engage in the learning activities and be able to participate in classroom activities as outlined in the teaching and learning material designed for that purpose. Creativity is an essential element of critical thinking. Finding ways in which classroom discourses would occur without compromising leaners' autonomy and empowerment would assist language instructors to practice what they preach regarding the use of critical thinking skills in problem solving.

\subsection{Social Nature of Learning}

As we have seen in social nature of learning, language learning is social practice, with multiple sources of knowledge besides teachers or individuals interacting with the learners. The current teaching and learning approaches recognize the need for other avenues at the University to provide opportunities for learners to learn the language. In the university under study, efforts have been made towards providing additional avenues where students can learn the language apart from the classroom. Such efforts include the establishment of Language Resource Centre, (which was renamed as the centre for African and International languages, to enable it expand its mandate beyond being selflearning resource access point, to becoming a knowledge sharing centre) and encouraging instructors in other disciplines to interact with learners in English both in the classroom and outside the classroom. The efforts also involve encouraging instructors in other disciplines to reinforce students language skills acquired in language classes while marking students' written texts. These measures were taken in the understanding that in the Tanzanian context, English language is not often used outside the classroom and therefore there was need of providing more opportunities for learners to practice language skills acquired in class outside classroom [14].

The assessment of this element shows the prevalence of limited response towards taking advantage of using these additional avenues for learning. Study findings (students' questionnaires) indicate that the demands for additional assistance in the language learning are overwhelming; however, students' learning efforts in this aspect are constrained by many things; one of them is the fact that English is still not a functional language outside the classroom. This factor implies that there is lack of a platform for students' language use and practice outside the language classroom. For example, the language learning centre, which was envisaged to become a referral point for students in need of assistance on language matters, has become a little more than an extension of academic staff offices and a venue for Departmental meetings. This is partly because awareness raising in the benefits of making optimal use of the resource has not received the envisaged positive response among the university community members.

Furthermore, instructors from other content subjects have continued to pay little attention to students' language performance in those content subjects. This is partly due to the traditional mind-set among academic staff at the university under study that language issues are the domain of language units or departments. This trend also raises other questions regarding the need for lecturers to scrutinise their own linguistic practices in the classroom This is especially because the indifference of subject content instructors from active participation in students' language learning might not necessary result from their reluctance of sharing responsibility; it might result from the reality that such instructors may also be linguistically challenged themselves, see also [3]. This is also an area which has not received much attention although it continues to undermine the efforts which are being made by language Units and Department in responding to the paradigm shift by transforming language use as social practice in the University under reference and in Tanzanian higher learning in general

Needless to say, Lecturers too are the product of the same widely criticised education system that students have gone through. Moreover, lecturers too have been shaped by the same social cultural backgrounds, even though these cultural backgrounds may have impacted the generations of students and lecturers differently due to differences in time [3]

\subsection{Curricular Integration}

Curricular integration fits well with CLT paradigm shift which considers the nature of language acquisition to be spiral or non-linear, that is, the idea of learners encountering a language concept many times before fully grasping it and thus benefitting from repeated exposure to related concepts [6]. As cited earlier, the Current CSCs curricular were revised to reflect more communicative context for the grammar topics with the addition of themes for each unit (gender roles, crime, and career goals). In the case of CSCI, the grammar topics were re-aligned within these units in the course material to reflect the "spiral" (non-linear) and integrated nature of language acquisition, building in complexity with each unit. For example, the use of tenses as a topic is presented across themes namely, Gender roles, Crime, and Career goals, across levels under Unit 1, Unit 2, and Unit 3 for CSC1 as shown in Table 1. 
Table 1. CSCI example topics and skills focused.

\begin{tabular}{lll}
\hline Unit 1 & Theme & Verb Learning Outcomes \\
\hline \multirow{2}{*}{ Unit 2} & Gender Roles & Identify and use present tenses: present simple/continuous \\
& Theme & Verb Learning Outcomes \\
& Crime and Accidents & Identify and use past tenses: past simple/continuous \\
\multirow{2}{*}{ Unit 3} & Identify and use perfect aspect: present perfect, past perfect \\
& Theme & Verb Learning Outcomes \\
& Career Goals & Identify and use tenses to talk about future time: will, going to, present continuous \\
\hline
\end{tabular}

Source: adopted from CSC I course Outline, 2016

A similar model was applied to the CSCII curriculum whereby the units were arranged in terms of themes (analyzing a problem, evaluating sources, and creating a solution) with the corresponding academic skills outcomes, integrating reading/writing/listening/speaking skills within them (See Table 2). Study findings (classroom observations and questionnaires) revealed that this approach had a huge positive impact in students' learning because firstly, students encountered similar topics several times, and this simplified their learning. Secondly, the arrangement of topics by themes helped students to make sense of what they were learning, and especially because the themes based on their local context.

Table 2. CSCII example topics and skills focused.

\begin{tabular}{|c|c|c|c|c|}
\hline Unit and Theme & $\begin{array}{l}\text { Critical } \\
\text { Thinking } \\
\text { Focus }\end{array}$ & $\begin{array}{l}\text { Listening and Speaking Learning } \\
\text { Outcomes }\end{array}$ & Reading Learning Outcomes & Writing Learning Outcomes \\
\hline $\begin{array}{l}1 \\
\text { Define and Analyze a } \\
\text { Problem in your Field }\end{array}$ & Analyze & $\begin{array}{l}\text { Determine strategies for improving } \\
\text { listening skills }\end{array}$ & $\begin{array}{l}\text { Recognize and examine different types of } \\
\text { academic writing (research proposal, term } \\
\text { papers, research report, project report) for } \\
\text { their purpose and elements }\end{array}$ & $\begin{array}{l}\text { Organize information and write } \\
\text { paragraphs in the following } \\
\text { patterns: Cause effect, descriptive, } \\
\text { narrative }\end{array}$ \\
\hline Unit and Theme & $\begin{array}{l}\text { Critical } \\
\text { Thinking } \\
\text { Focus }\end{array}$ & $\begin{array}{l}\text { Listening and Speaking Learning } \\
\text { Outcomes }\end{array}$ & Reading Learning Outcomes & Writing Learning Outcomes \\
\hline $\begin{array}{l}2 \\
\text { Evaluating Evidence }\end{array}$ & Evaluate & $\begin{array}{l}\text { Analyze critically essentials of } \\
\text { effective oral presentation/public } \\
\text { speaking }\end{array}$ & $\begin{array}{l}\text { Recognize and examine different types of } \\
\text { academic writing (experiments) for their } \\
\text { purpose and elements } \\
\text { Interpret components of essay questions }\end{array}$ & $\begin{array}{l}\text { Plan and write an essay (with } \\
\text { logical paragraphing and } \\
\text { sectioning ) in response to essay } \\
\text { questions from students' } \\
\text { disciplines }\end{array}$ \\
\hline Unit and Theme & $\begin{array}{l}\text { Critical } \\
\text { Thinking } \\
\text { Focus }\end{array}$ & $\begin{array}{l}\text { Listening and Speaking Learning } \\
\text { Outcomes }\end{array}$ & Reading Learning Outcomes & Writing Learning Outcomes \\
\hline $\begin{array}{l}3 \\
\text { Creating A Solution }\end{array}$ & Create & $\begin{array}{l}\text { Compose appropriately various } \\
\text { coherent talks in writing } \\
\text { Use argumentative language and } \\
\text { logic to express opinions in speaking }\end{array}$ & $\begin{array}{l}\text { Recognize and examine different types of } \\
\text { academic writing (abstracts) for their } \\
\text { purpose and elements }\end{array}$ & $\begin{array}{l}\text { Use argumentative language and } \\
\text { logic to express opinions in } \\
\text { writing } \\
\text { Organize information and write } \\
\text { paragraphs in the following } \\
\text { pattern: argumentative }\end{array}$ \\
\hline
\end{tabular}

Source: adopted from CSC II course Outline, 2016

Another aspect worth commenting on is the authenticity of the examples used in class for different areas of disciplines and or specialization. Students were expected to define and analyze a problem that is present in their area of study. For example, students in Agriculture Science could choose to examine issues such as soil erosion; education students could choose to examine issues such as low performance in a school; students in tourism could choose to examine issues on customer care, recreational sites or ecotourism. The use of authentic examples was envisaged to make students see the value of what they learn in class and its applicability outside the classroom. And secondly, these examples were envisaged to increase students' vocabulary and knowledge in their areas of specialization.

Study findings from students' questionnaires revealed that students were less cognizant with high level intellectual skills. For example, students' responses to writing outlines in analyzing essay questions showed little evidence of analysis, evaluation or creativity. This Aspect is partly attributed to questioning practices students are exposed to in pre university studies. In other words, prior university training is more towards lower level skills, namely knowledge, understanding and little application. These lower level skills though are relevant in pre-university studies; they still seem to permeate much of students' learning even at university level. At the university, students are expected to be more analytical, evaluative, or creating in their answers, but teaching approaches (lecture methods) and questioning practice (focused on lecture notes) work against development of higher level cognitive skills among students as this instructors confesses,

I give my students lecture notes because I know... that... 
that there are no textbook,... you know?

And you know what.... I don't give my students anything outside my notes, you see..1 Uh... because if I do, they would say... you know ... you have not taught us this or that ...thing. This is ... is of kind of students (laugh) and I don't want to invite problems (laugh). (Staff interview, November 2017

In the University under study, the curricular review referred to above went hand in hand with the development of teaching and learning materials. Despite the fact that the curricular and learning materials empower students to interact with the materials, the findings of the study (interview and students questionnaires) indicate that students do not benefit from this aspect due to students poor reading culture. One instructor had this to say

When I tell..uh... my students about the virtues of reading, uh... very few uh ....seem to understand me. One day, uh... I asked my students in uh... a language class, uh... apart from chapters and or sections of textbooks in their academic disciplines, how many of them uh... have read anything outside uh... their subject areas, or even for leisure; they all looked at me in amazement. Uh... To them, I was merely making strange nonsensical noises (Staff interview, November 2017).

Students' reading culture is context based in Tanzania. Extended reading is not a common practice in Tanzania, as reported in The Citizen, $11^{\text {th }}$ December 2011, 'Extensive research hasn't been conducted to assess reading habits amongst Tanzanians, but even casual observation reveals that interest in books has been progressively fading', and, more critically, threatening the country's civilization'. This trend in the context of this study was found to compromise student's potential in their development of cognitive skills in other domains.

\subsection{Focus in Meaning}

Regarding focus on meaning, the University under study apart from the revision of CSCs curricular, as explained above, it has also revised course material to make them more authentic, in the sense of reflecting students' culture, traditions, and customs. Grammar topics were also aligned with particular themes to have such topics more contextualised. This measure was taken to avoid rote learning, which as we have seen, though may have short term benefits; may not be beneficial in enhancing learners' communicative competence which is espoused in the CLT. The assessment aspect is as explained in the learner autonomy and curricular integration regarding students' interaction with learning materials.

\subsection{Teachers as co-Learners}

Teachers as co-learners augur well with the concept of lifelong learning where teachers take part in the never-ending quest for learning and, indeed, model this process for their students. In the University under study, the need for teachers' participation in the learning process was made more elaborate in the staff training. There was more emphasis in encouraging staff to realise that they were not reservoirs of knowledge; and that there was a lot they could learn from students, and that this knowledge needs not only be on subject matter contents, but it could also be on knowing something about students' learning difficulties. Such knowledge is a useful input for instructors in evaluating their own teaching methodologies, and thereby helping them to improve as they interact with students, that is, learning how to teach. The findings of the study (classroom observation) indicate that instructors seem to have been transformed by the training they undertook; for example, in the classroom sessions, instructors empowered learners, by giving rationale for the instructions they provided to them. Despite this seemingly leaners' empowerment by their instructors, as espoused in the CLT model, the classroom discourse practice had all indications that the transformation was not fully completed. Instructors' authority seem to permeate classroom discourse, which counters one of the model's cardinal principle that requires instructors to be co-learners in their process of learning students' behaviour as part of source of knowledge and of learning how to teach. This is precisely linked to lecture method of teaching, which is a one way traffic, which often takes a form of a master-servant relationship where lecturers dictate notes and students listen to or rather take down the notes uncritically.

\subsection{Alternative Assessment}

In the University under study, the equivalent of alternative assessment described in the Jacobs and Farrell, (2003) communicative framework is enshrined in the change of CSCI assessment criteria from dependence on summative tests and University examinations to include three unit exams and other communicative tasks such as interactive seminar presentation practices; group and individual work; small tasks and one final exam (see also [2, 15-18]. Furthermore, there was a shift in weighting of the assessments whereby more weight was allocated to continuous assessment than was the case in the final examination; this means, students were now to be more and more engaged on peer assessment and group tasks than was the case previously.

As for the assessment of CSCII, formative and summative tasks were included. Formative development tasks were meant to be provided for each lecture or interactive seminar, and these also include: an independent term paper project. This project is informed by the principles of Problem-Based Learning (PBL) whereby students define a problem of their choice and, through careful thought and research; they work towards creating a solution for that problem. The purpose of this methodology is to guide students in a learner-centred way to develop independence and gain academic and or language skills in the process. Thus, the project for CSCII uses this idea as a format for the course and its themes for the three units: Defining and Analysing a Problem, Evaluating Sources, and Creating a Solution. The end product is a term paper about a problem that students choose and investigate, and this term paper is to be written in parts throughout the 
three units of the course. The project aimed at giving students the opportunity to utilize the skills they are being introduced to in the CSC II, namely critical thinking at various levels (analysis, evaluation, and creation), academic writing in different forms, and discipline-specific content and forms of communication. The findings in this study (classroom observations, interviews, questionnaires) reveal that alternative assessment was highly constrained with large class sizes. For example, one instructor had this observation

I cannot grade all these classroom activities given large number of students. Imagine, you have three hundred or so students in a group. And you need to go through each individual student's paper. I don't know what others are doing but for me; it's impossible...! (Staff interview, November 2017)

Instructors also reported that they were unable to visit all working groups doing classroom activities more than once due to time limitation and the number of groups given the class sizes. Similarly, the term project which was meant to be done individually and test students' ability in critical thinking at various levels (analysis, evaluation, and creation), academic writing in different forms, and discipline-specific content and forms of communication could not be successfully implemented. Instead, according to staff interviews, students were put in groups of five to ten participants for the project. This could not allow testing of individual skills on the areas specified.

\subsection{Thinking Skills}

Given the importance of thinking skills, these skills have been integrated in the CSC II curriculum of the University under reference. And this has been done in a spiral manner where the skills have been linked to all other topics across the curriculum; details of these linkages are discussed under curricular integration.

As we have seen, this course is more focused on study skills, and so the inclusion and integration of critical thinking skills across levels, themes, and skills in the curriculum was considered to be one of the major changes in the revised curriculum. The study findings (curriculum review, classroom observation) indicate that despite that critical thinking was integrated in all the topics of the curriculum, instructors treated language skills (reading, Writing, speaking, and listening), within each unit vertically and in isolation; each skill was taught within the given time limit without consideration of other skills at the same time. More importantly, it was also observed that instructors taught about the skills and not how to enable learners to acquire and practice the skills. During staff interview, instructors admitted to have been teaching not only about individual language skills but also, that the skills were handled in isolation as one of the instructors says,

There are many challenges in integrating skills because firstly, not all the skills are examined in university assessment, for example listening and speaking; secondly, there are no teaching media in enhancing some of the skills such as listening or speaking (Instructors' interview

\section{December, 2016}

The assumption here is that when I speak students are already doing listening, I give students some reading tasks, thus I assume that this is enough opportunity for them to read (Instructors' interview December, 2016)

All said, there is limited evidence from one instructor who seemed to have integrated thinking skills in writing in the following extract of the example writing assignment given to students

\section{Practice 1.1: Who thinks more critically in writing?}

The following texts have been reproduced verbatim from Mozambican students (labelled A, B, and C) who are giving their accounts of their experiences in learning English language at a university in Tanzania. Read the texts and then do the activities that follow them.

Working in groups of 5 people, look at the student' texts again and using taxonomy of cognitive learning domains (see Blooms taxonomy) decide on the following.

1. Which of the students $\mathrm{A}, \mathrm{B}$, and $\mathrm{C}$ is focusing more on higher level skills in his/her writing (i.e. he/she is doing analysis, evaluation, and so on)? Give example sentences and the skills demonstrated to support your answer

Student:

Critical thinking skills demonstrated

Example sentences from the text:

2. Which of the students $\mathrm{A}, \mathrm{B}$, and $\mathrm{C}$ is focusing more on lower level skills in his writing (i.e. provides information recall and memory)? Give example sentences and the skills demonstrated to support your answer

Student:

Critical thinking skills demonstrated

Example sentences from the text:

After finishing answering the questions compare your answers with those of another pair and discuss points of differences.

As surmised above, similar examples from other instructors of integrating thinking skills across the curriculum were nonexistence. It needs to be pointed out however that the implementation of CLT curriculum requires ingenuity on the part of the instructors responsible to link all the skills across all the topics when implementing the curriculum [19, 20]. Secondly, instructors need to realise that they need to create the environment in which learners will be able to participate in the skills acquisition. And as pointed out in learner autonomy, Creativity is an essential element of critical thinking. The need for instructors to find ways in integrating these elements in the classroom discourses would augur well with the demands of CLT curriculum and thereby make language instructors practice what they themselves preach regarding the use of critical thinking skills in problem solving.

\subsection{Diversity}

As we have seen in the new paradigm, students are considered as individuals with diverse interests, identities and individualities which ought to be taken into account when learning. When learners juxtapose different languages, 
discourses, styles, and approaches they gain substantively in metacognitive and metalinguistic abilities and in their ability to reflect critically on complex systems and their interactions [12].

From this standpoint, the role of University and literacy pedagogy is not to require one culture and linguistic standard instead these institutions must be strong as neutral arbiter of "difference" (see [12]). In the context of the University under study, as is the case in many other universities in Tanzania, the Communication Skills course is the only structural framework within which students' arbitration of this cultural difference ought to take place, within the new paradigm. In the university under study as is the case with any other university, students are from diverse backgrounds, in terms of social, linguistic, and cultural profiles. The study findings (classroom observation) indicate that instructors did not seem to be sensitive to students' individual identities, and individualities, instead students were all treated equally. Such a treatment did not augur well with the paradigm shift, which is as already said; in a language classroom, Teachers' role is to arbitrate this cultural and linguistic diversity as "classroom resource just as powerful as it is a social resource in the formation of new civic spaces and new notions of citizenship" [12].

The reasons which seem to constrain the adoption of this element of the paradigm are the same provided in Learners' autonomy, where it seems impractical for instructors to provide all the students with the individual attention they deserve owing to time available for the course and class sizes. It is worth reiterating here that in order for the paradigm shift to succeed there is need for deliberate efforts for institutions to review the teaching and learning systems so that students have enough time to engage in the learning activities which would enable them to articulate their individualities for confidence building and self-actualisation.

\section{Discussion}

As for the learner autonomy, we have seen that students do not benefit from the autonomy given to them because of poor reading skills. This implies that students learning process is highly compromised because if one cannot read effectively it means that one's' access to knowledge is severely jeopardized and this has severe negative consequences in students' academic performance in universities in Tanzania. In this respect, universities have a role in devising a mechanism of encouraging reading culture among students. Since, the reading problem has a background on students' pre university education; universities ought to liaise with agencies dealing with pre-university education, first to raise awareness of the magnitude of the problem and at the same time to see what role universities can play in enhancing students' reading abilities at this level. This is especially, because secondary schools are the major catchment for university students. There is a need for secondary schools and universities to establish a common forum where universities would provide feedback to secondary schools on the competences required of students when entering universities and deficiencies students' bring with them to universities. Conversely, secondary schools would feedback universities on the challenges secondary schools experience in addressing students' gaps in those areas of competencies.

With regards to social nature of learning, we have seen in the findings section that the demands for additional assistance in the language learning are overwhelming. Students are however constrained by the fact that English is not a functional language outside classroom. This implies that students have limited opportunities to practice language in real life situations. This aspect becomes an impediment for the University to implement a paradigm shift espoused in the Jacobs and Farrell's model. It is therefore important for the University to have an institutional framework which would encourage students and instructors to use English as a functional language on campus. It is envisaged that enabling environment for students to use English in real communication would enable them attach the use of English language to meaningful purposes. Studies [2, 3, 21], show that English language as a medium of education in Tanzania his highly politicized, with ideological undercurrent which focused on setting English versus Kiswahili as antagonistic languages and especially of making English a source of problems in the education system in Tanzania. These ideological currents have had some implications in the discursive practices of secondary and higher education, leading to a bulk of pedagogical mediocrity and students' academic underachievement at all levels of education, see for example [3].

As for curricular integration, we have seen that to make the CSCs curricular more communicative with the addition of themes for each unit and the re-arrangement of the units to reflect the "spiral" (non-linear) and integrated nature of language acquisition, had a huge positive impact in students. This is because firstly, students encountered similar topics several times, and this simplified their learning. Secondly, the arrangement of topics by themes helped students to make sense of what they were learning, and especially because the themes based on their local context. The implication is that this approach helps students to make use of background knowledge and progressively acquire content knowledge within the themes. Furthermore, it helps students to engage in more productive discussions and activities which increase the depth of the language learning. This is one of the best practices which universities across the country can adopt in reviewing curriculum for their CSCs courses. Similarly, content course materials could be used to design language course materials. Language course materials which are developed from content courses provided on campus provide students with the skills they need to be successful in their other college or university courses. As we have seen in the previous sections, teachers as co-learners augur well with the concept of lifelong learning where teachers take part in the never-ending quest for learning and that despite the fact that instructors seem to have been empowering students as espoused in the Jacobs and Farrell's model, there are 
indications that instructors' discourse practices are deficient in transforming these classroom discursive spaces into neutral grounds for equal participation. Instructors' authority in all of the classes observed was found to permeate classroom discourse. This is inconsistent with one of the model's cardinal principles that require instructors to be colearners in their process of learning students' behaviour as a source of knowledge and of learning how to teach. The main implication in this aspect is that despite attending training on new teaching approaches instructors still cling in their old ways. One reason for this could be that instructors' prior university training did not orient them into approaches which they had to adopt as instructors. Instead instructors were exposed to these new approaches espoused in the paradigm shift within a short period of time during departmental training workshop retreat. This could not have made a big impact into transforming such instructors to fully being able to change their practices as well as mind set. It is recommended therefore that training on pedagogies across universities in Tanzania should incorporate concepts in the new approaches in their main stream curriculum and become a regular practice in the in-service training.

Departmental retreats are one of the areas which could work in place of in-service training, which are often costly due to meagre available resources in our universities. In such retreats, instructors could share knowledge on best practices and challenges encountered in meeting their common goals. There has been a lot of discussion on the need of instructors in other subjects working with language instructors in addressing some of the notorious learning difficulties among students. Ironically, apart from scheduled departmental meetings which are often focused on examination results and academic teaching calendars there is little evidence in the university under study of the existence of language instructors common forum dealing with sharing experiences on classroom practices.

The evaluation of alternative assessment component in the implementation of new curriculum within the paradigm shift model has revealed challenges which are mainly to do with class sizes at the University under study. It is reported elsewhere [14] that large class sizes is a phenomenon which is common in many universities in the African continent and which has been caused by pressures for students expansion and massification. Such a trend is said to have reached '... a critical stage where the lack of resources has led to a severe decline in the quality of instruction and in the capacity to reorient focus and to innovate" [22]. Many universities simply have to make do with limited staff and facilities available. Now since it may not be practical to require universities to cut down the sizes of students' population, it seems inevitable for universities to invest in human capacity building in handling large class sizes. In fact, large class size has far reaching implications in the implementation of the new curriculum within the paradigm shift framework with regards to all the components in the framework, although however, the impact is severe on such components as alternative assessment, diversity, as well as critical thinking skills.

\section{Conclusion}

The current study intended to assess the implementation of the revised curricular. Specifically, the study wanted to find out how successfully the revised curricular has been implemented in meeting the objectives of the changing trends in the teaching of English towards more communicative approaches in what is referred to here as paradigm shift. A few successes were observed in the implementation of the new approach especially in the area of curriculum integration where the concept of spiral and non-linear arrangement of topics proved to be quite effective in students learning.

Secondly, the study sought to identify challenges which emerged during the implementation of the curricular and the associated approaches. A number of challenges inherent in the implementation of the new approach in the context of University under study and Tanzania generally were identified, and these revolved around large sizes, learner cantered, reading habits and critical thinking skills.

And also, these findings were found to have far reaching implications in the implementation of the new curriculum within the paradigm shift framework with regards to all the components in the framework. It is therefore recommended that universities in Tanzania create an environment in which the elements proposed in the paradigm shift can be effectively implemented. Some of the measures universities can adopt include investing in self-learning resource centres as additional avenues for learning outside classroom, encourage reading culture, capacity building in handling large class sizes, as well as collaboration with pre university levels especially secondary schools in working out common grounds of addressing the earmarked problems through exchange of experience and best practices.

\section{References}

[1] J. Mwakapina, A. Mhandeni and O. S. Nyinondi, "WhatsApp Mobile Tool in Second Language Learning: Opportunities, Potentials and Challenges in Higher Education Settings in Tanzania," International Journal of English Language Education, vol. 4, no. 2, pp. 70-90, 2016.

[2] O. S. Nyinondi, A. S. Mhandeni and H. I. Mohamed, "The use of communicative language teaching approach in the teaching of communication skills courses in Tanzanian universities," International Journal of Research Studies in Language Learning,, vol. 6, no. 3, pp. 89-99, 2017.

[3] S. C. Komba and H. I. Mohamed, "Towards re-defining communication skills courses at Sokoine University of Agriculture: Lessons from selected African Universities," International Journal of Research Studies in Language Learning, pp. 1-13, 2016.

[4] J. Crandall and D. Kaufman, Content Based Instruction in Higher Education Settings, Maryland: TESOL, 2002.

[5] G. M. Jacobs and T. S. C. Farrell, "Understanding and implementing the CLT (Communicative Language Teaching) paradigm," RELC Journal, vol. 34, no. 1, pp. 5-30, 2003. 
[6] J. C. Richards, Communicative Language Teaching Today, UK: Cambridge University Press, 2006.

[7] M. A. Snow and D. Brinton, The Content Based Classroom: New Perspectives in Integrating language and Content, 2nd ed., Michigan: New University of Michigan Press, 2018.

[8] M. Breen and C. Candlin, "The essentials of a communicative curriculum in language teaching.," Applied Linguistics,, vol. 1, no. 2 , pp. $89-112,1980$.

[9] M. A. K. Halliday and C. M. I. M. Matthiessen, "Construing Experience through Meaning: A Language-based Approach to Cognition," Computational Linguistics, vol. 27, no. 1, pp. 140-142, 1999.

[10] H. Widdowson, Teaching Language as Communication, London: Oxford University Press. 1978.

[11] L. Anderson, D. Krathwohl, P. Airasian, K. Cruikshank, R. Mayer, P. R. J. Pintrich and M. Wittrock, A Taxonomy for Learning, Teaching, and Assessing: A revision of Bloom's Taxonomy of Educational Objectives., New York: Pearson, 2001.

[12] B. Cope and M. Kalantzis, "A pedagogy of Multiliteracies designing social futures," in Multiliteracies: Literacy Learning and the Design of Social Futures, B. Cope and M. Kalantzis, Eds., London, Routledge, 2000, pp. 9-37.

[13] Department of Language studies, Students Activity Book, Morogoro: Sokoine University of Agriculture, 2014.

[14] H. I. Mohamed and O. S. Nyinondi, "How Tanzanian Universities Can Respond to Increasing Market Demands of Specialized Forms of English Language Learning and Communication Skills," Journal of English Language, vol. 6, no. 2, pp. 1-9, 2016.
[15] L. K. Heilenman, "Self-Assessment of Second Language Ability: the Role of Response Effects," Language Testing, vol. 7, no. 2, pp. 174-201., 1990 .

[16] B. Peirce, M. Swain and D. Hart, "Self-Assessment, French Immersion, and Locus of Control," Applied Linguistics, vol. 14 , no. 1 , pp. 25-42, 1993.

[17] G. Wiggins, "Toward more authentic assessment of language performances," in Teaching, testing, and assessment: Making the connection. Northeast conference reports, C. Hancock, Ed., IL, National Textbook Co, 1994.

[18] K. Yap, "Integrating assessment with instruction in ABE/ESL programs," in The annual meeting of the American Educational Research Association, 1993.

[19] M. C. Tama, "Critical Thinking: Promoting It in the Classroom,” ERIC Digest, pp. 1-4, 1989.

[20] E. Üstünlüog, "Language Teaching through Critial Thinking and Self-Awareness," English Teaching Forum, pp. 2-8, July 2004.

[21] H. I. Mohamed and F. Banda, "Classroom Discourse and Discursive Practices in Higher Education in Tanzania," Multilingual and Multicultural Developments, vol. 29, no. 2, pp. 95-109, 2008.

[22] R. M. Kavuma, In Africa's Universities, quantity threatens quality, vol. p 2, The Guardian, 2011. 